\title{
Some salient features of the atmosphere observed over the north Bay of Bengal during BOBMEX
}

\author{
G S BHAT \\ Centre for Atmospheric and Oceanic Sciences, Indian Institute of Science, Bangalore, India. \\ e-mail:bhat@caos.iisc.ernet.in
}

This paper describes the near surface characteristics and vertical variations based on the observations made at $17.5^{\circ} \mathrm{N}$ and $89^{\circ} \mathrm{E}$ from ORV Sagar Kanya in the north Bay of Bengal during the Bay of Bengal Monsoon Experiment (BOBMEX) carried out in July-August 1999. BOBMEX captured both the active and weak phases of convection. SST remained above the convection threshold throughout the BOBMEX. While the response of the SST to atmospheric forcing was clearly observed, the response of the atmosphere to SST changes was not clear. SST decreased during periods of large scale precipitation, and increased during a weak phase of convection. It is shown that the latent heat flux at comparable wind speeds was about $25-50 \%$ lower over the Bay during BOBMEX compared to that over the Indian Ocean during other seasons and tropical west Pacific. On the other hand, the largest variations in the surface daily net heat flux are observed over the Bay during BOBMEX. SST predicted using observed surface fluxes showed that 1-D heat balance model works sometime but not always, and horizontal advection is important. The high resolution Vaisala radiosondes launched during BOBMEX could clearly bring out the changes in the vertical structure of the atmosphere between active and weak phases of convection. Convective Available Potential Energy of the surface air decreased by $2-3 \mathrm{~kJ} \mathrm{~kg}^{-1}$ following convection, and recovered in a time period of one or two days. The mid tropospheric relative humidity and water vapor content, and wind direction show the major changes between the active and weak phases of convection.

\section{Introduction}

The convective systems that frequently form or intensify over the Bay of Bengal are critical for the summer rainfall over the Indian subcontinent. Despite its economic and scientific importance, there have been very few atmospheric observational studies carried out over the Bay during the monsoon period. Two major experiments conducted over the Bay prior to 1999, namely the monsoon experiment of 1977 (called MONSOON-77, e.g., Mohanty and Das 1986) and the monsoon experiment of 1979 (called MONEX-79, Fein and Kuettner 1980) were more than 20 years back. The emphasis in the earlier experiments was on understanding the large-scale aspects of monsoon circulation. MONEX-79, in particular, has provided the planetary and regional scale features of the monsoon (e.g., Krishnamurti 1985). One of the main limitations of the earlier experiments is that the observation period over the Bay was less than two weeks, and the active and weak phases of monsoon could not be adequately captured. Further, an issue that has received considerable attention in the last 20 years is the ocean-atmosphere variations and coupling on intraseasonal time scales, and accurate estimation of surface fluxes. For example, while the initial emphasis in the decade long international observational programme "Tropical OceanGlobal Atmosphere" (TOGA) was on interannual climate variability, a special process study called "Coupled Ocean-Atmosphere Response Experiment" (COARE) was subsequently planned and executed over the west Pacific warm pool as part

Keywords. Monsoon; air-sea coupling; tropical convection; boundary layer. 


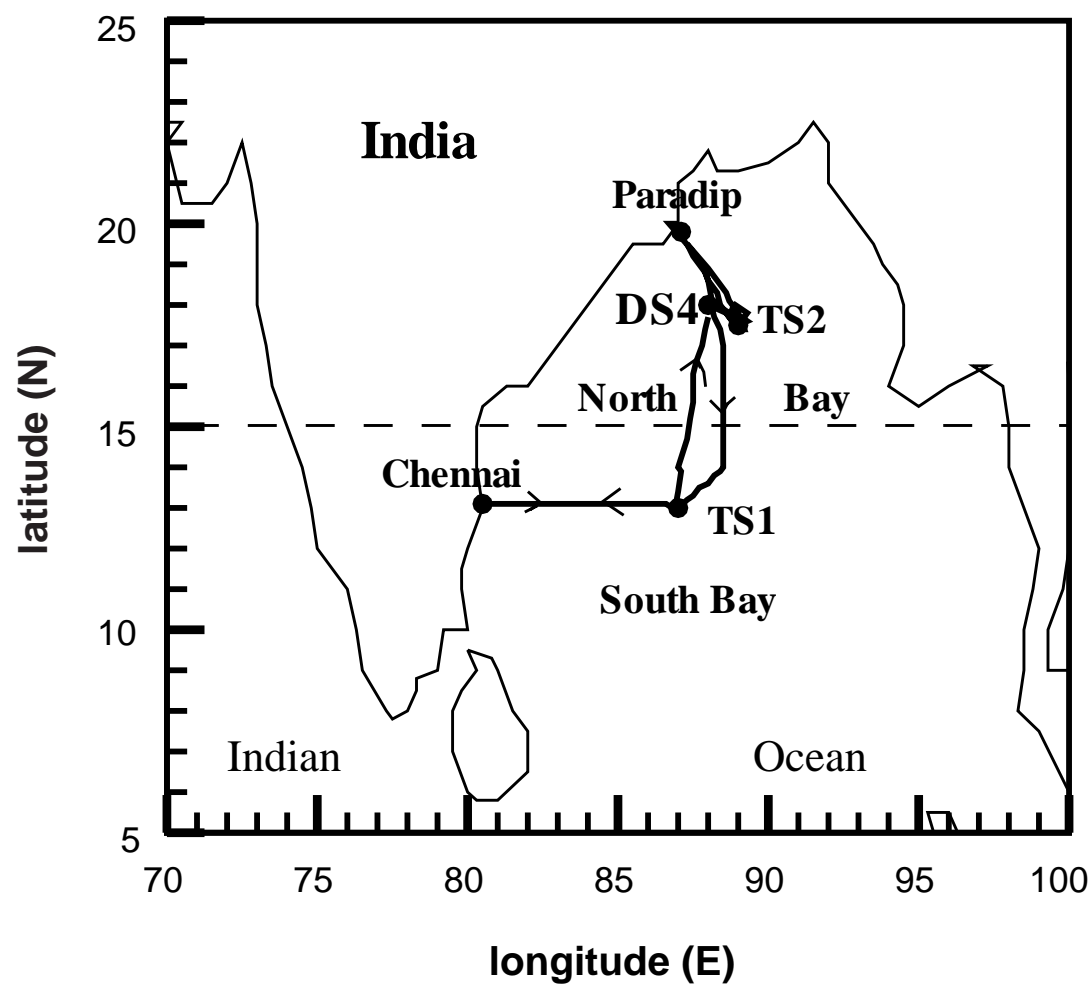

Figure 1. Cruise tracks and the time series observation stations (TS1 \& TS2) in the Bay of Bengal during BOBMEX. Observation positions: TS1 $-13^{\circ} \mathrm{N}, 87^{\circ} \mathrm{E}$; TS2 $-17.5^{\circ} \mathrm{N}, 89^{\circ} s \mathrm{E}$. DOD's moored buoy in the head Bay is located at DS4 $\left(18^{\circ} \mathrm{N}, 88^{\circ} \mathrm{E}\right)$. The present study describes observations made at TS2 from ORV Sagar Kanya.

of TOGA to address ocean-atmosphere coupling on the intraseasonal time scale of 30-60 days (Webster and Lukas 1992; Godfrey et al 1998). Intraseasonal oscillations in SST have been observed over the Bay also (Krishnamurti et al 1988), however, its amplitude in the 30-60 day mode is found to be smaller compared to that over the west Pacific. Data from recently deployed moored buoys in the Bay showed that both SST and wind were modulated on intraseasonal timescales during the monsoon period and suggested a strong coupling between the ocean and the atmosphere (Premkumar et al 2000). Buoy data revealed that the dominant time scale of intraseasonal oscillation (ISO) over the Bay was 3-4 weeks, i.e., less than that over the west Pacific. The precise nature of the ocean-atmosphere variations and their coupling during active and weak phases of monsoon was not addressed until very recently.

Since the Bay is a critical area for the Indian monsoon, the first observational programme under the Indian Climate Research Programme (ICRP) was planned and conducted over the Bay. This experiment, called "Bay of Bengal Monsoon Experiment" (BOBMEX) was entirely an Indian effort and was carried out during July-August 1999. The scientific background, main objectives and field phase of BOBMEX are described in Bhat et al (2001). The major objectives of BOBMEX included the atmospheric variations and nature of air-sea coupling during active and weak phases of monsoon. The emphasis in BOBMEX was on time series observations from two locations in the southern and northern Bay (henceforth referred to as TS1 and TS2 respectively, see figure 1). Indian research vessels INS Sagardhwani and ORV Sagar Kanya were deployed at TS1 $\left(13^{\circ} \mathrm{N}, 87^{\circ} \mathrm{E}\right)$ and TS2 $\left(17.5^{\circ} \mathrm{N}, 89^{\circ} \mathrm{E}\right)$, respectively.

Recognizing the importance of the Asian monsoon on the global climate, an international experiment, called "The Joint Air-Sea Monsoon Interaction Experiment" (JASMINE) was carried out in 1999 over the tropical Indian Ocean with intraseasonal variability of the south Asian monsoon as a major focus (Webster et al 2002). Phase I (April 7th-22nd) and Phase II (May 1st-June 8th) of JASMINE were carried out from the US research ship Ronald H. Brown, and Phase III (September 2nd-28th) was carried out from the Australian research ship R/V Franklin. The area of observations was centered along the $89^{\circ} \mathrm{E}$ longitude line between $5^{\circ} \mathrm{S}$ and $16^{\circ} \mathrm{N}$, with more number of observations taken around $12^{\circ} \mathrm{N}$ in the Bay. JASMINE data revealed that wind and humidity structures in the troposphere change significantly 
between the active and weak phases of ISO. The mean surface fluxes during the weak and active phases of ISO were $+90 \mathrm{Wm}^{-2}$ and $-89 \mathrm{Wm}^{-2}$ respectively. On comparison with the west Pacific warm pool characteristics, it was concluded that the results of the west Pacific warm pool experiments cannot simply be transferred to the Indian Ocean (Webster et al 2002).

Convection shifts to the north Bay normally in late May and early June, and July-August are peak monsoon months. The major fraction of JASMINE observations was taken around $12^{\circ} \mathrm{N}$ (Webster et al 2002). The northernmost extent of the JASMINE cruise was $16^{\circ} \mathrm{N}$, that too in April when convection is normally active towards south of $15^{\circ} \mathrm{N}$. Therefore, BOBMEX is the first experiment to collect observations during a peak monsoon period in the north Bay using modern flux sensors and high resolution radiosondes. BOBMEX followed JASMINE with a gap of about 6 weeks, and we expect the observations carried out during BOBMEX (particularly at TS2) to complement JASMINE observations.

The present paper is mainly based on the measurements made at the time series station TS2. The main focus is on the salient features of the atmosphere observed at TS2. It is shown that the monsoonal atmosphere over the north Bay has special features not normally observed during other seasons and over the western Pacific warm pool.

\section{Data}

ORV Sagar Kanya was positioned at TS2 from 27th July to 24th August 1999 with a break (port call) during 6 th -13 th August. Henceforth, the periods 27th July to 6th August and 13th to 24th August are referred to as phase I and phase II respectively. The basic surface meteorological variables measured were wind, temperature (dry bulb, wet bulb and sea surface), humidity, pressure, radiation and precipitation. The selection and calibration of the instruments used on ORV Sagar Kanya, and intercomparison with other in situ data during BOBMEX are discussed in Bhat et al (2001) and Bhat (2002). The measurement accuracies achieved on ORV Sagar Kanya met the accuracy levels of $0.25^{\circ} \mathrm{C}$ and $0.2 \mathrm{~ms}^{-1}$ (or $2 \%$, whichever is larger) for air temperature and wind speed respectively, sought by the World Ocean Circulation Experiment (WOCE) programme for observations over the oceans (e.g., Hosom et al 1995). The uncertainty in the relative humidity was $2 \%\left(\sim 0.5 \mathrm{gm} \mathrm{kg}^{-1}\right.$ in the mixing ratio), which is marginally higher than the WOCE requirement of $1.7 \%$. (WOCE specification on the accuracy of the mixing ratio is more stringent at
$0.25 \mathrm{gm} \mathrm{kg}^{-1}$.) Radiosondes (Vaisala model RS80$15 \mathrm{G}$ ) were launched from the ship. The frequency of radiosonde launch varied between 2 and 5 per day depending on the synoptic conditions and weather advice.

\section{Results}

\subsection{The synoptic setting}

During the period 25th July to 9th August, India Meteorological Department (IMD) declared three monsoon systems in the region, namely, a depression, a low and again a depression during 27th29th July, 2nd -4th August and 6th-8th August, respectively (Bhat et al 2001). These systems formed/intensified over the north Bay, moved onto the subcontinent and produced wide spread rainfall over India. During phase II, few deep convective systems were seen over the observation area, however, these systems decayed over the Bay itself and did not develop into monsoon systems. The daily outgoing longwave radiation (OLR) averaged for the area $15^{\circ}-20^{\circ} \mathrm{N}$ and $82.5^{\circ}-92.5^{\circ} \mathrm{E}$ is shown in the top panel in figure 2 . It is observed from figure 2 that there were several occasions when OLR was below $175 \mathrm{Wm}^{-2}$. Except for the $15 \mathrm{th}-16 \mathrm{th}$ August event, other low OLR events were associated with the monsoon systems declared by IMD. Further, the daily OLR was below $240 \mathrm{Wm}^{-2}$, a value often associated with deep convection (Graham and Barnett 1987), throughout phase I and during most of phase II. The surface pressure was about $7 \mathrm{mb}$ lower during phase I (mean $999 \mathrm{mb}$ ) compared to that during phase II (mean $1006 \mathrm{mb}$ ) (figure 2). All the three monsoon systems formed during the period when the average surface pressure was low. An important question that arises is, was the average surface pressure low because of convection and formation of the monsoon systems, or a larger (planetary) scale circulation gave rise to a low pressure regime which was conducive for the development of monsoon systems, that in turn consolidated the low pressure regime further. Previous studies have shown that the size and duration of convective systems depend on the phase of ISO. For example, over the tropical west Pacific, long living, large (deep) cloud systems characterize the active ISO period, whereas, the weak phase of ISO is characterized by short lived and smaller cloud systems (Chen and Houze 1997). Was the lower surface pressure during phase I and higher pressure during phase II a manifestation of the ISO over the north Bay? Present observations are suggestive but not adequate to answer this question unambiguously. The connections between the development of the monsoon systems versus the phase of ISO needs 

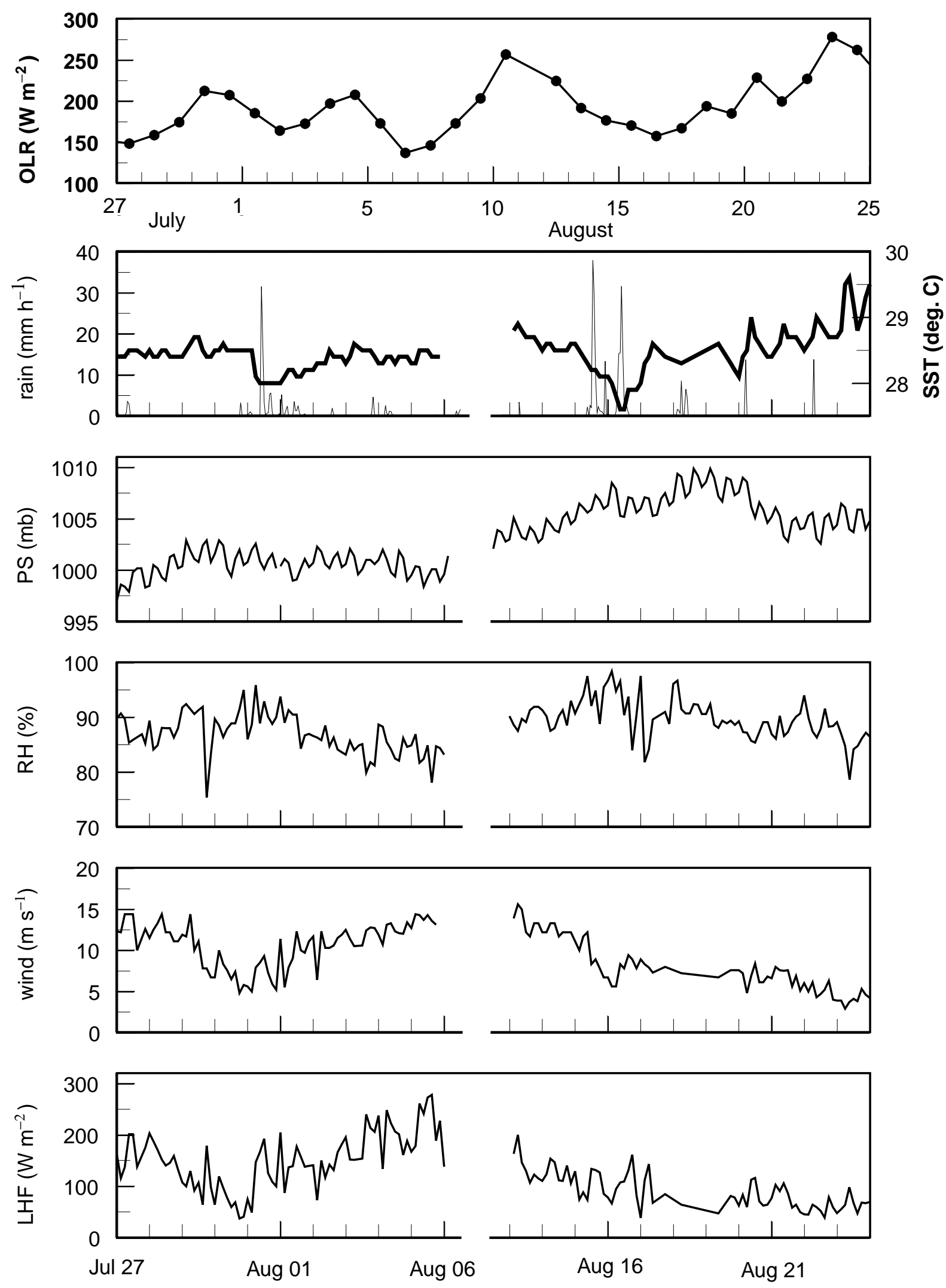

Figure 2. INSAT daily OLR for the $15^{\circ}-20^{\circ} \mathrm{N}$ and $82.5^{\circ}-92.5^{\circ} \mathrm{E}$ box in the north Bay of Bengal, SST, hourly rainfall, surface pressure (PS), relative humidity $(\mathrm{RH})$, wind speed and the latent heat flux (LHF) at TS2. 


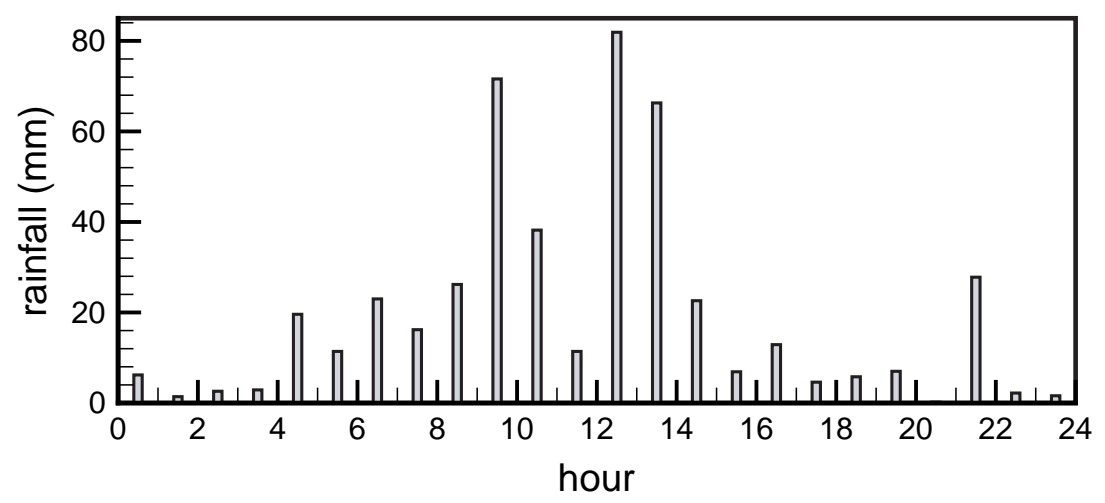

Figure 3. Diurnal variation in rainfall at TS2. Rainfall shown is obtained by adding the precipitation that occurred during respective hourly intervals for all days having total daily rainfall of more than $2 \mathrm{~mm}$.

to be explored as this is an important problem and has potential application in the advance prediction of the development of a monsoon system.

Rainfall exceeding $50 \mathrm{~mm}$ occurred on 31st July, 6th August, and 15th-16th August. (Since the ship moved away from TS2 on 6th August, rainfall data for that day is incomplete.) A closer examination of rainfall revealed a prominent diurnal variation with more rainfall favored around local afternoon hours (figure 3 ) and the period between 2100 LST and early morning hours being the least preferred time. This pattern of diurnal variation is different from that of early morning peaks normally observed over open tropical oceans (e.g., Chen and Houze 1997; Gambheer and Bhat 2001). SST was above the convection threshold value of $28^{\circ} \mathrm{C}$ (Gadgil et al 1984) throughout except for a brief period on August 16th. SST remained around $28.5^{\circ} \mathrm{C}$ during phase I and showed a larger variation from less than $28^{\circ} \mathrm{C}$ to more than $29.5^{\circ} \mathrm{C}$ during phase II. On 31st July, TS2 station received $80 \mathrm{~mm}$ of rainfall and SST decreased by about $0.4^{\circ} \mathrm{C}$. A larger decrease of $0.9^{\circ} \mathrm{C}$ was observed during 15th-16th August when the TS2 station received about $200 \mathrm{~mm}$ total rainfall. From 19th to 24th August, the sky was nearly clear of deep clouds over TS2 and a prominent diurnal variation in SST is seen. Thus, modulation of SST by the atmosphere was clearly seen during BOBMEX. Average wind speeds varied from less than $3 \mathrm{~ms}^{-1}$ to more than $15 \mathrm{~ms}^{-1}$ during the BOBMEX period, with the average wind during phase $\mathrm{I}\left(\sim 10 \mathrm{~ms}^{-1}\right)$ higher than that during phase II $\left(\sim 7.5 \mathrm{~ms}^{-1}\right)$. It may be mentioned here that gust winds exceeding $18 \mathrm{~ms}^{-1}$ have been observed on few occasions for brief periods just ahead of an approaching rain belt. RH was between $85 \%$ and $90 \%$ most of the time, and exceeded $90 \%$ during rains. The specific humidity of the surface air decreased marginally (by $1-2 \mathrm{gm} \mathrm{kg}^{-1}$ ) during rains (Bhat 2001). It is important to note here that evaporation of falling rain drops decreases the temperature of the surface air and increases the relative humidity (air temperature approaches the wet bulb temperature). In such cases, the specific humidity of the air increases. However, during convective episodes, both temperature and specific humidity decreased at TS2 (Bhat 2001). Simultaneous decrease in the temperature and specific humidity of the surface air is possible only if air having a lower moist static energy from above the cloud base reached the surface (Betts 1976).

\subsection{Surface fluxes}

The latent heat flux (LHF) shown in the last panel in figure 2 is based on the bulk algorithm described in Zeng et al (1998). This algorithm uses the Monin-Obukhov similarity theory for the convective surface layer, and is observed to agree well with the directly measured TOGA-COARE fluxes. Measurements that enable the direct computation of the latent heat flux using the eddy correlation method were made during BOBMEX also. The results obtained so far indicate good agreement between the LHF obtained from the bulk algorithm of Zeng et al (1998) and that obtained from the eddy covariance method using BOBMEX data (differences between the two are typically less than $10 \%$ ). LHF varied in the $40-280 \mathrm{Wm}^{-2}$ range. It is observed from figure 2 that the variation in LHF closely follows that of the wind speed. This is not unexpected as LHF depends on the mean wind speed, however, there is an important difference in the variation of LHF with wind speed between other tropical oceans and the Bay. LHF at TS2 was substantially lower compared to that over the western Pacific warm pool at comparable wind speeds (figure 4). For example, at a wind speed of $8 \mathrm{~ms}^{-1}$ LHF was around $100 \mathrm{Wm}^{-2}$ at TS2, whereas, the corresponding value over the Pacific warm pool is about $150 \mathrm{Wm}^{-2}$ (Fairall et al 1996), i.e., $50 \%$ 


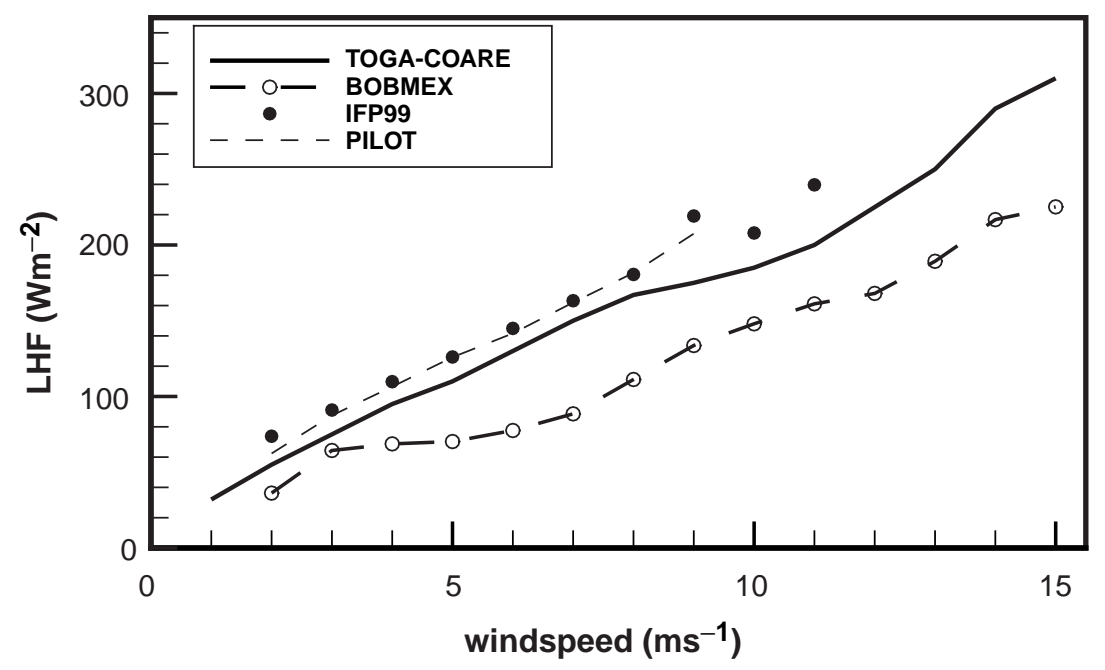

Figure 4. Mean variation of the latent heat flux with wind speed observed during TOGA-COARE, BOBMEX, IFP99 and BOBMEX-Pilot experiments.

higher. Also shown in figure 4 are the variations of LHF with wind speed measured from ORV Sagar Kanya during INDOEX intensive field phase in 1999 (IFP99, e.g., Mitra 1999; Bhat et al 2003) and BOBMEX-Pilot (henceforth Pilot, e.g., Bhat et al 2000). IFP99 data were collected over the tropical Indian Ocean during January-March 1999 (i.e., northern hemispheric winter), and the Pilot data were collected over the southern Bay during October-November 1998, i.e., during the post monsoon period. The same set of instruments was used during IFP99, Pilot and BOBMEX. Therefore the differences in LHF between BOBMEX, IFP99 and Pilot are due to factors other than instrument differences. The latent heat fluxes at a given wind speed are comparable during TOGACOARE, IFP99 and Pilot, however, that during BOBMEX is lower by $30-40 \%$. The main factor responsible for the lower values of LHF during BOBMEX is the high amount of water vapor in the air during the monsoon period. While typical values of relative humidity over the tropical oceans are $75-80 \%$, those observed during BOBMEX were often in the $85-90 \%$ range. As a result, the specific humidity difference between the sea surface (saturated over the saline water at SST) and air at $10 \mathrm{~m}$ height was typically in the $3-4 \mathrm{~g} \mathrm{~kg}^{-1}$ range during BOBMEX compared to values of $5-7 \mathrm{~g} \mathrm{~kg}^{-1}$ normally observed over the tropical oceans. Therefore, although the winds were much stronger during the summer monsoon, the surface cooling due to evaporation of water was not proportionately higher.

The daily net surface heat flux $Q_{\text {net }}$, defined as $Q_{\text {net }}=\mathrm{NSW}-(\mathrm{NLW}+\mathrm{LHF}+\mathrm{SHF})($ where NSW is net shortwave radiation, NLW is net longwave radiation and SHF is sensible heat flux), is computed for days when incoming shortwave and longwave radiation data are available in addition to LHF and sensible heat fluxes. Outgoing components of radiation were measured only during BOBMEX. For IFP99 and Pilot cruises, outgoing longwave and reflected shortwave radiation are computed assuming 0.95 sea surface emissivity and $5 \%$ albedo, respectively. LHF and shortwave radiation were the largest terms in the surface heat flux. Normally, the sensible heat flux was less than $10 \mathrm{Wm}^{-2}$. The average value of net longwave radiation was 40 to $50 \mathrm{Wm}^{-2}$ during IFP99 and Pilot experiments, but was much lower $\left(20-30 \mathrm{Wm}^{-2}\right)$ during BOBMEX. $Q_{\text {net }}$ is shown in figure 5. (Flux into the ocean is taken as positive.) The net heat flux basically followed the synoptic conditions. When convection was active, depleted shortwave radiation and increased LHF due to stronger winds resulted in substantial net heat loss. The reverse was taking place during the weak phase of convection. During IFP99, net heat flux varied from $-90 \mathrm{Wm}^{-2}$ to $120 \mathrm{Wm}^{-2}$. The corresponding range was $-240 \mathrm{Wm}^{-2}$ to $220 \mathrm{Wm}^{-2}$, and $-140 \mathrm{Wm}^{-2}$ to $100 \mathrm{Wm}^{-2}$, respectively during BOBMEX and PILOT. During JASMINE, carried out over the Bay of Bengal during April-June 1999, net heat flux values ranged from $-150 \mathrm{Wm}^{-2}$ to $125 \mathrm{Wm}^{-2}$. Therefore, the largest variations in the net heat flux among the recent experiments over the Indian Ocean are seen during the peak monsoon period in the north Bay of Bengal. Webster et al (2002) report that the intraseasonal variability of the fluxes observed during JASMINE was larger than that encountered during TOGA-COARE in the western Pacific Ocean. Although the present time series are not long enough to clearly bring out the intraseasonal variations, the range of BOB- 

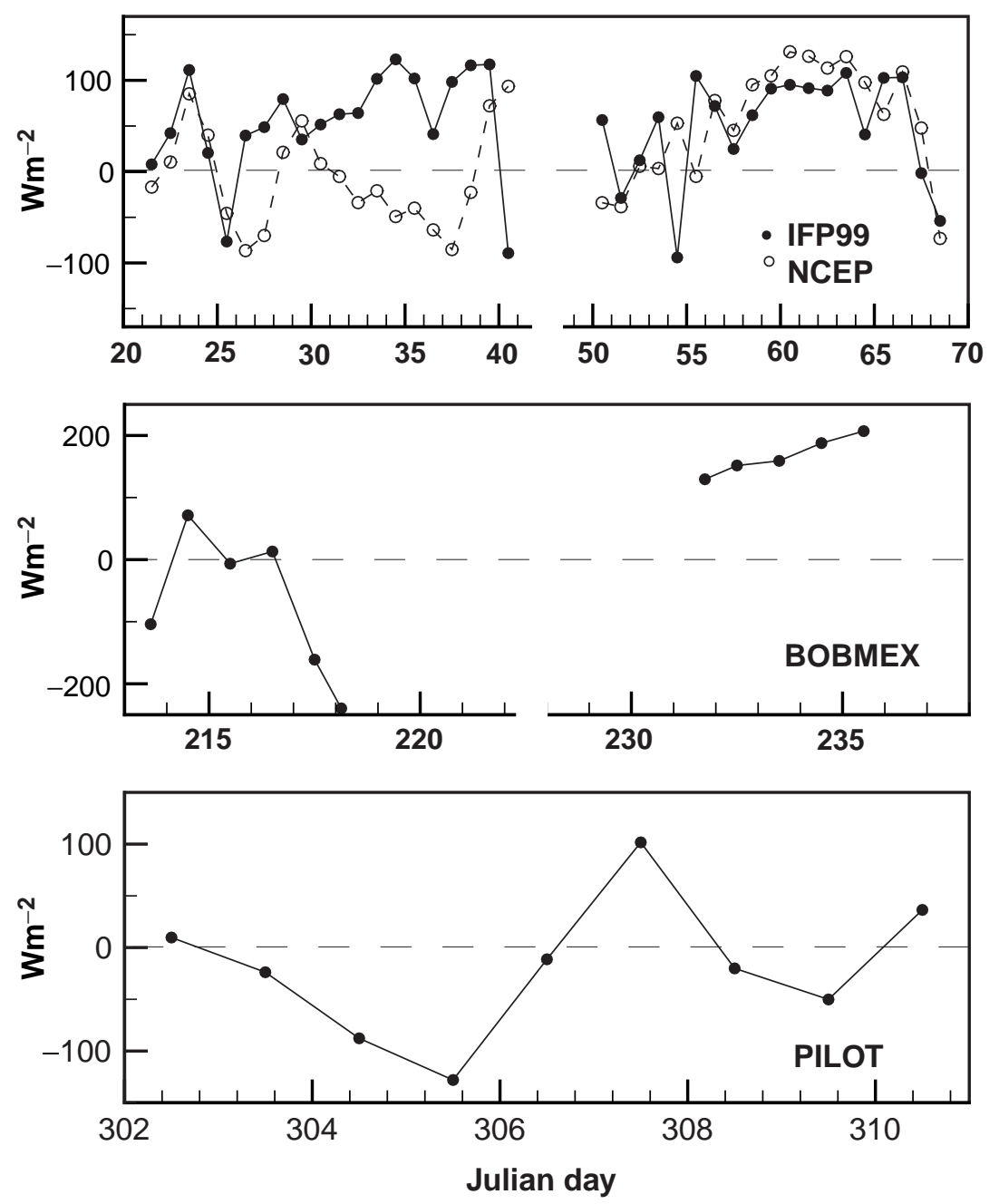

Figure 5. Daily net surface heat flux during IFP99, BOBMEX and BOBMEX-Pilot experiments. Also shown along with IFP99 data is NCEP reanalysis net surface heat flux.

MEX net heat flux variations are larger than those observed during JASMINE, and support the observation made by Webster et al (2002) that variations in the net heat flux are largest over the Bay of Bengal during the monsoon.

Among the three experiments, namely Pilot, IFP99 and BOBMEX, IFP99 was the longest (20th January to 10th March) and the total observation period was more than 40 days. This period is reasonably long enough to compare in situ and model reanalysis data. Since NCEP reanalysis data is one of the frequently used products by the research community, I have considered here the NCEP reanalysis surface fluxes. The NCEP reanalysis daily net surface heat flux, corresponding to the grid box where the ship was located on the respective day of observation during IFP99, is shown in the top panel in figure 5. In general, the agreement between the two is better in the north Indian Ocean and poorer in the south Indian Ocean. When the individual components of the heat flux are examined, it is observed that ship and NCEP reanalysis net longwave, latent heat and sensible heat fluxes are in reasonable agreement with each other (Bhat et al 2003). Good and poor agreement in $Q_{\text {net }}$ mainly resulted from differences in the net shortwave radiation, the largest component of $Q_{\text {net }}$ (Bhat et al 2003).

\subsection{SST evolution}

One of the questions asked from the very planning stage of BOBMEX was the role of surface heat fluxes in the SST evolution. All components of radiation, namely, incoming and outgoing components of shortwave and longwave radiation, were measured at TS2. Also sensible and latent heat fluxes have been computed. Therefore, the net surface heat flux could be computed. I used a 1-dimensional mixed layer model forced by the surface heat flux to explore the SST evolution at TS2. Neglecting a minor contribution from the 

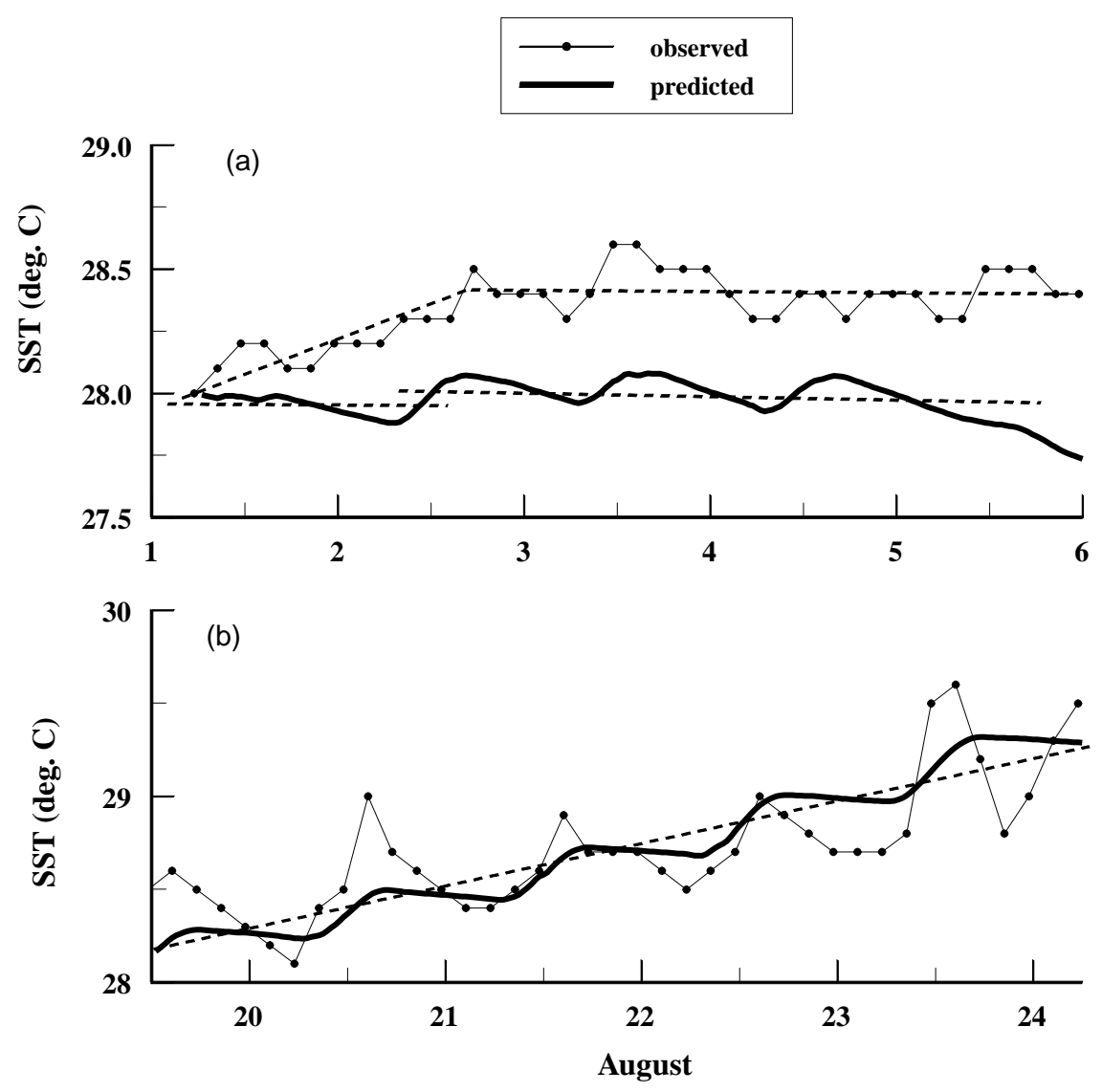

Figure 6. Observed SST and the predicted temperature of the mixed layer using 1-D heat balance model. Day shown is with respect to the local time. Dashed lines are drawn to indicate the mean trends in the temperature.

rainfall, the evolution of the temperature of the top layer of the ocean is given by (e.g., Bradley et al 1993),

$$
\begin{aligned}
& \rho_{w} C_{w} \partial(h T) / \partial t=Q(t)-R_{T}(h)+ \\
& {\left[\rho_{w} C_{w} \kappa \partial T / \partial z\right](h)+A_{h}+A_{z} }
\end{aligned}
$$

where $\rho_{w}$ and $C_{w}$ are the density and specific heat of water, $h$ is depth of the layer under consideration (here taken as the mixed layer depth (MLD)), $T$ is the average temperature of the layer, $R_{T}$ is the downward transmission of shortwave radiation at depth $h, \kappa$ is the eddy diffusivity of heat, $A_{h}$ and $A_{z}$ are the horizontal and vertical transport of heat by advection. Assuming a constant value of $h$ and ignoring the diffusion and advection terms, the temporal evolution of $T$ is given by,

$$
T(t)=T_{0}+\int_{0}^{t}\left[Q\left(t^{\prime}\right)-R_{T}(h)\right] \mathrm{d} t^{\prime} /\left(\rho_{w} C_{w} h\right) .
$$

Apart from the net heat flux $Q$, the time evolution of $T$ depends on the assumed value of $h$ (namely MLD), and $R_{T}$, the amount of shortwave radiation passing through the bottom of the mixed layer unabsorbed.
The vertical profiles of water temperature, salinity and density, and the estimation of MLD during BOBMEX are discussed in Vinayachandran et al (2002) and Bhat et al (2001). In the north Bay salinity plays a dominant role. Examination of the CTD profiles taken at TS2 during BOBMEX suggested that the MLDs were in the 10-15 $\mathrm{m}$ range (Vinayachandran et al 2002). In the following calculations, $14 \mathrm{~m}$ and $13 \mathrm{~m}$ are assumed for MLD during the first and third weeks of August respectively. Mixed layer depth is taken to be slightly larger during phase I as winds were much stronger during this period (figure 2). $R_{T}$ is an important parameter when MLD is small, however $R_{T}$ was not measured during BOBMEX. Here $15 \%$ of the net shortwave radiation received at the surface is assumed to pass through the bottom of the mixed layer without being absorbed by water (Paulson and Simpson 1981).

The predicted water temperature from equation (2) is compared with the observed SST in figure 6 for two occasions in August which were nearly free of rain. (During periods of heavy or continuous rains, the uncertainty in the measured/computed fluxes is more, and hence such periods are not included in the present calculations.) Predicted 
and observed temperature trends are not in agreement with each other during the first two days of August, but compare well on other days. During 1st-3rd August, while the predicted temperature is nearly constant, observed SST increased by about $0.5^{\circ} \mathrm{C}$. It is to be noted from figure 6 (a) that SST increased during night hours as well, a period during which there was a continuous loss of heat from the surface. Therefore, the SST increase cannot be attributed to the surface heat fluxes but to the advection of warmer water. The surface salinity decreased rapidly from more than $30 \mathrm{psu}$ to $28.5 \mathrm{psu}$ during the corresponding period (Bhat et al 2001). Local precipitation could account for less than $0.5 \mathrm{psu}$ change in salinity (Vinayachandran et al 2002). Therefore, the salinity change was mainly due to horizontal advection of water from another place, thus supporting the conclusion based on mixed layer heat budget analysis that horizontal advection was dominating the surface variations in the first week of August. The predicted water temperature and observed SST are in good agreement with each other during the 19th24th August period except for the larger amplitude of diurnal variation in the observed SST. During the 19th-24th August period, solar insolation was high and the latent heat losses were relatively small. Fairall et al (1996a) argue that the top two meters of the ocean absorbs roughly $50 \%$ of the net solar radiation, and in the absence of vertical mixing, can keep increasing the temperature of this layer uniformly by $2^{\circ} \mathrm{C}$ on clear sky days. The warmer water eventually gets mixed throughout the mixed layer due to wind stirring. This process was taking place at TS2 during the 19th-24th August period resulting in a stronger diurnal cycle in the observed SST as compared to the mixed layer average temperature.

Thus, the results shown in figure 6 show that both horizontal advection and surface net heat flux are important in maintaining the high SST in the north Bay during the summer monsoon. As already pointed out earlier (figure 5), during the weak phase of convection, the net heat flux into the ocean is around $200 \mathrm{Wm}^{-2}$, which, as already discussed, is significantly large when compared to other seasons over the Indian Ocean. This, combined with a shallow mixed layer of the north Bay created by a strong salinity stratified layer enables the SST to increase by more than $1^{\circ} \mathrm{C}$ in just $4-$ 5 days. A $1^{\circ} \mathrm{C}$ increase in SST above $28^{\circ} \mathrm{C}$ takes the overlying atmosphere from convection threshold to peak convection level (Waliser et al 1993). Thus, within a few days after a convective episode occurred, the sea surface conditions become ready to support another event of deep convection over the Bay.

\subsection{Atmospheric stability and vertical variations}

One of the major objectives of BOBMEX was to understand the response of the atmosphere to convection and changes in the vertical stability of the atmosphere. As already discussed, both convective and clear sky conditions were encountered during BOBMEX at TS2. For the present purpose, periods with substantial rainfall (total rainfall associated with the convective event more than $50 \mathrm{~mm}$ ) are considered as convective periods ( $\mathrm{CP}$, consists of days July 31st - August 1st, August 6th and 15th16th August). During 19th-24th August, the sky was clear of deep clouds and substantial heating of the ocean took place. This was a weak phase of convection (WPC) over the Bay, and the average for this period is taken as representative of such a phase. Next, properties of the atmospheric mixed layer and that of the troposphere at TS2 during active and WPC are discussed.

\subsubsection{Mixed layer}

Atmospheric mixed layer is that part of the atmosphere that continuously interacts with the underlying surface. The energy from the surface is first received by this layer and then transported upwards by convective processes. Therefore, it is important to understand the fluctuations in the properties of the mixed layer during active and weak phases of convection. Here the mixed layer height $(\mathrm{MLH})$ is defined as the height from the surface above which the virtual potential temperature $\theta_{v}$ increases (rapidly) with height. $\theta_{v}$ is approximately constant within the mixed layer. Figure 7(a) shows MLH observed at TS2. The average MLH was about $500 \mathrm{~m}(\sim 50 \mathrm{mb})$. The MLH responded to synoptic conditions and varied from less than $100 \mathrm{~m}$ to $900 \mathrm{~m}$, with the larger heights normally observed during the weak phase of convection. MLH became shallow (less than $200 \mathrm{~m}$ ) following a rain spell. After the rains stopped, MLH regained the normal value within two days. The average as well as the range of MLHs observed at TS2 are comparable to those observed during TOGA-COARE (Godfrey et al 1998).

Figure 7(b) shows the variation of average value of the water vapor mixing ratio in the lowest $50 \mathrm{mb}$ layer $\left(q_{\mathrm{ml}}\right)$. (Since $50 \mathrm{mb}$ is the average MLH, average of the lowest $50 \mathrm{mb}$ layer is referred to as the mixed layer property henceforth for the convenience of reference, although, as already discussed, the actual MLH was not constant at TS2.) The average value of $9 \mathrm{ml}$ is between 18 and $19 \mathrm{gm} \mathrm{kg}^{-1}$. When convection was active, values of $q_{\mathrm{ml}}$ decreased by $\sim 10 \%$, due to convective down- 

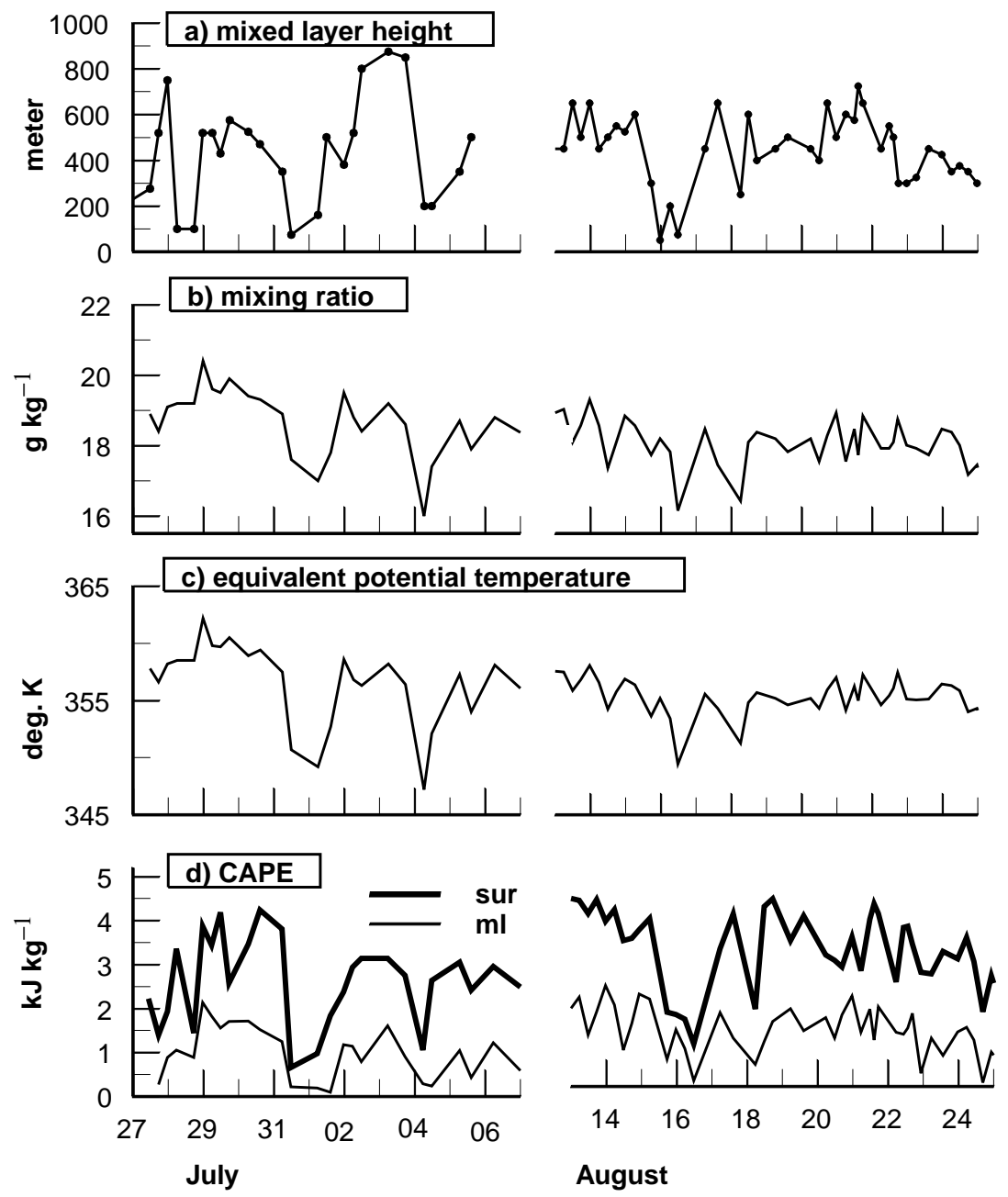

Figure 7. Temporal variation of mixed layer height, mixed layer average water vapor mixing ratio, mixed layer equivalent potential temperature and mixed layer CAPE. Also shown in the last panel is the CAPE of the surface air.

drafts (Betts 1976), and recovered within two days after rains stopped. Surface evaporation can easily account for this recovery period (Bhat 2001). It is observed that while SST increased by more than $1^{\circ} \mathrm{C}$ during 19th -24 th August, there was no corresponding increase in the amount of water vapor in the mixed layer. (Apart from SST, the strength of air-sea coupling decides the amount of water vapor in the mixed layer, which to a large extent depends on the wind speed, e.g., Bhat 2002.) Figure 7(c) shows the equivalent potential temperature $\left(\theta_{e}\right)$ of the mixed layer $\left(\theta_{\mathrm{eml}}\right) . \theta_{\mathrm{eml}}$ varied in $347 \mathrm{~K}$ to $362 \mathrm{~K}$ range. The decrease in $\theta_{\mathrm{eml}}$ during convectively active periods is in the $10-14 \mathrm{~K}$ range and $\theta_{\mathrm{eml}}$ increased to the pre-convective range within two days after rains stopped. The range of (surface) $\theta_{e}$ observed in the Pacific warm pool area during TOGA COARE was $345 \mathrm{~K}$ to $365 \mathrm{~K}$ (Kingsmill and Houze 1999) and the values observed at TS2 are comparable to those over the Pacific warm pool area.
Critical parameters for the atmospheric convection are the convective available potential energy (CAPE), a measure of the vertical instability of the atmosphere (Moncrief and Miller 1976). Figure $7(\mathrm{~d})$ shows the variation of CAPE of the surface air $\left(\mathrm{CAPE}_{\text {sur }}\right)$ and the average value for the mixed layer $\left(\mathrm{CAPE}_{\mathrm{ml}}\right)$ during BOBMEX. $\left(\mathrm{CAPE}_{\mathrm{ml}}\right.$ is calculated by taking the mean of the individual CAPE of air parcels lifted in $5 \mathrm{mb}$ intervals.) The highest value of $\mathrm{CAPE}_{\text {sur }}$ exceeded $4 \mathrm{~kJ} \mathrm{~kg}^{-1}$. The mean values of CAPE and $\mathrm{CAPE}_{\mathrm{ml}}$ are around $3 \mathrm{~kJ} \mathrm{~kg}^{-1}$ and $1 \mathrm{~kJ} \mathrm{~kg}^{-1}$ respectively. CAPE decreased during the active phase of convection and the amount of instability destroyed by the deep convection, as measured by the decrease in CAPE, is $2-3 \mathrm{~kJ} \mathrm{~kg}^{-1}$ for the surface air and about $1 \mathrm{~kJ} \mathrm{~kg}^{-1}$ for the mixed layer air. The recovery time of both CAPEs is 1 to 2 days. The range of CAPE observed at TS2 and TOGACOARE are comparable (Kingsmill and Houze 1999). 

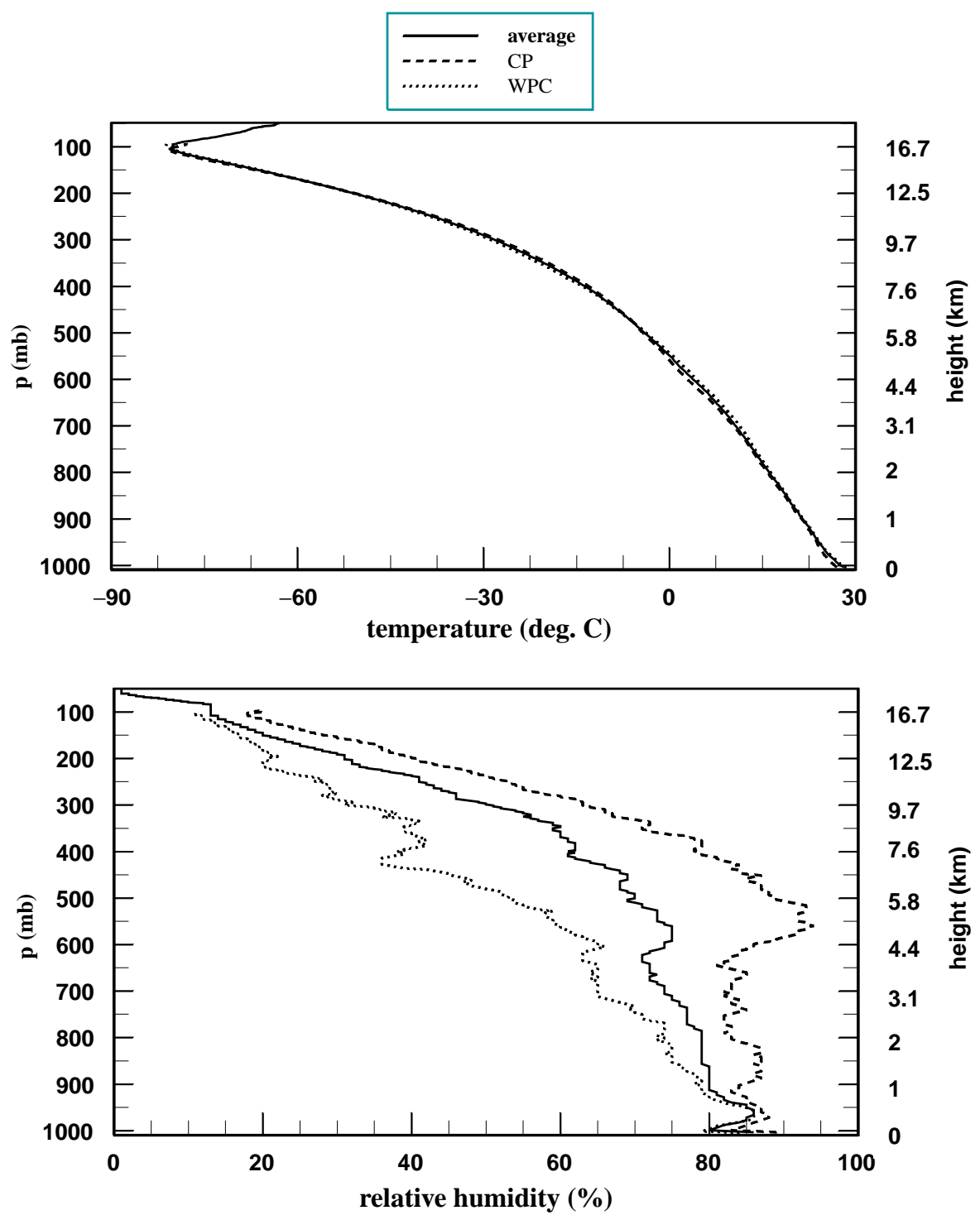

Figure 8. Vertical profiles of temperature (top) and relative humidity (bottom) during active and weak phases of convection along with the observation period average.

The recovery of the time scale of CAPE suggests that thermodynamic conditions become favorable for another active phase of convection in just one or two days after a disturbance passed over the area. Positive (and sufficiently large) CAPE is a necessary but not sufficient condition for deep convection. To realize the instability however, large scale dynamical conditions (low level convergence in particular) need to be favorable. For example, on August 18th, CAPE had recovered, deep clouds started developing and about $30 \mathrm{~mm}$ rainfall was recorded. However, the system dissipated, probably due to unfavorable large scale conditions for the convection to intensify. The high frequency of convection over the Bay means that not only the thermodynamic recovery of the atmosphere is rapid, large scale conditions also become favorable frequently (perhaps in the form of perturbations of sufficient magnitude) during the monsoon period. There are indications from the visual inspection of satellite imageries that the travelling disturbances from west Pacific and equatorial Indian Ocean intensify over the Bay. The precise nature of the large scale control on convection as well as the sources of perturbations needs to be investigated further for the Bay.

\subsubsection{Vertical profiles}

To start with, let us consider the average sounding for the entire period at TS2 (referred to as the average sounding), and the departures from the average during active and weak phases of convection. As already stated, the frequency of radiosonde launch varied between 2 and 5 per day. In order to remove the bias of the average sounding towards 


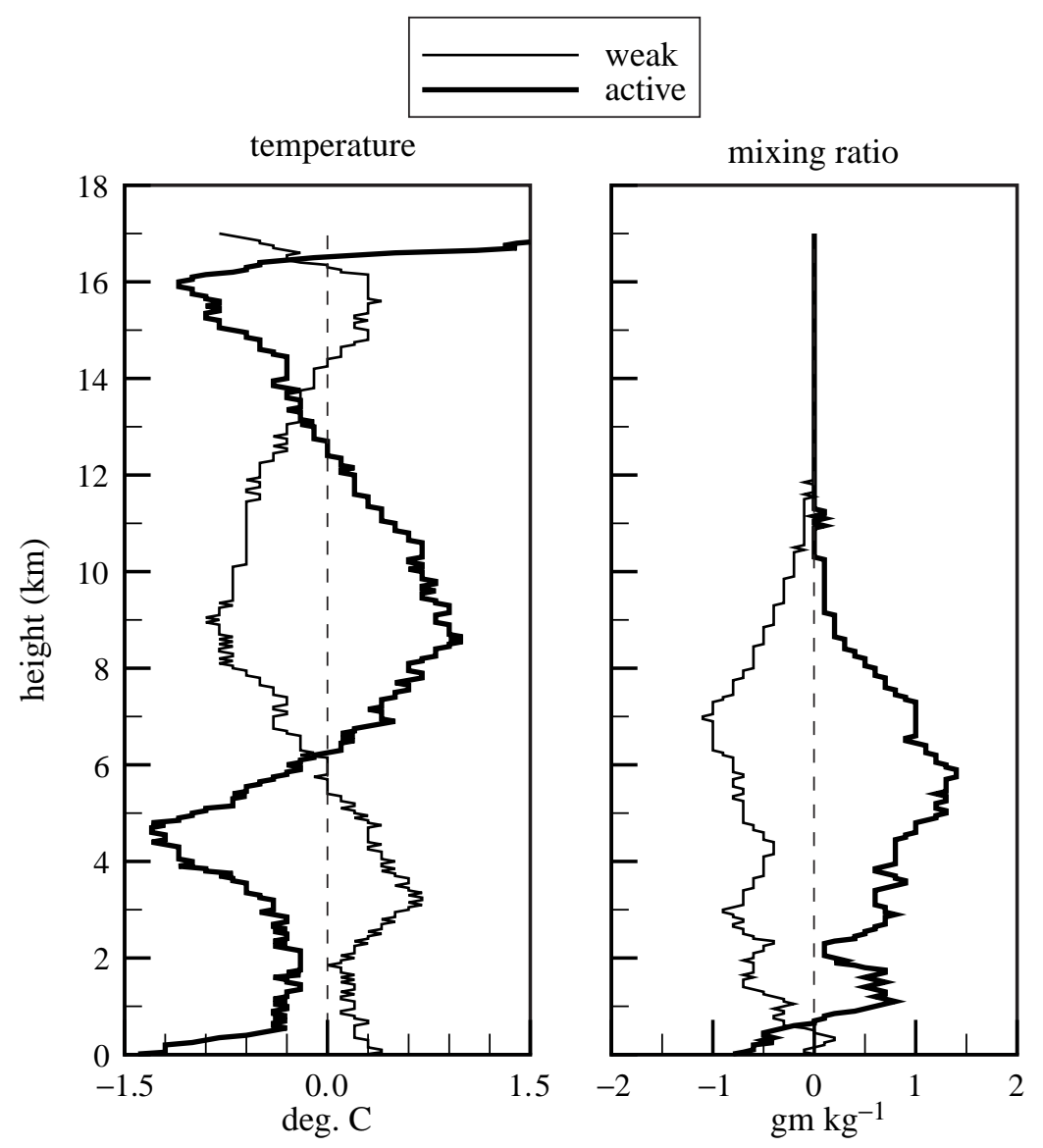

Figure 9. Anomalies of temperature and water vapor mixing ratio during the active and weak phases of convection.

days with more frequent soundings, the average sounding is calculated by considering the morning (00 UTC) and evening ( 12 UTC) soundings for each day. The average soundings for the active and weak periods of convection are averages of all available soundings for the respective periods. The average sounding is an average of 24 days of radiosonde data, and CP and WPC soundings are averages of 5 days each.

Figure 8 shows the vertical profiles of average air temperature and relative humidity, and figure 9 the anomalies (i.e., departure from the average) of temperature and mixing ratio during active and weak convective periods. Maximum temperature departure from the average were less than $1.5^{\circ} \mathrm{C}$ (figure 9); this change is small compared to more than $110^{\circ} \mathrm{C}$ decrease observed between the surface and the tropopause (figure 8). Therefore, temperature profiles appear more or less identical in figure 8 . On the other hand, changes in the humidity field are more prominent. Relative humidity $(\mathrm{RH})$ increased particularly in the middle troposphere during the convective period, and the entire troposphere became drier during WPC; the largest changes occurred between $600 \mathrm{mb}$ and $300 \mathrm{mb}$ levels (figure 8). There is a clear difference in the temperature and humidity anomalies between convective and WPC periods (figure 9). During the convective period, the average temperature in the lowest 6 kilometers (below $490 \mathrm{mb}$ ) decreased, that in the 6 to 13 kilometers ( $490 \mathrm{mb}$ to $185 \mathrm{mb}$ ) layer became warmer, and above 13 kilometers the temperature decreased. The physical processes responsible for the decrease in the temperature near the surface and humidity anomaly are discussed later. The large cooling between $5 \mathrm{~km}$ and $6 \mathrm{~km}$ heights is due to melting of the ice when frozen hygrometeors in deep convective clouds descend below the zero degree centigrade isotherm. During the WPC period, the lower troposphere was warmer, mid troposphere was colder and a warmer layer near the tropopause was present.

Another quantity of interest is the variation of amount of water vapor in different layers, and is shown in figure 10. It is observed that the average integrated water vapor (IWV) amount was around $60 \mathrm{~kg} \mathrm{~m}^{-2}$ with extreme values of $52 \mathrm{~kg} \mathrm{~m}^{-2}$ and $68 \mathrm{~kg} \mathrm{~m}^{-2}$. The major contribution to the variation came from 850-300 mb layer, with the variations in the lowest $150 \mathrm{mb}$ layer and above $300 \mathrm{mb}$ being small. Thermals and shallow cumulus clouds (when present) continuously carry up and mix the water 

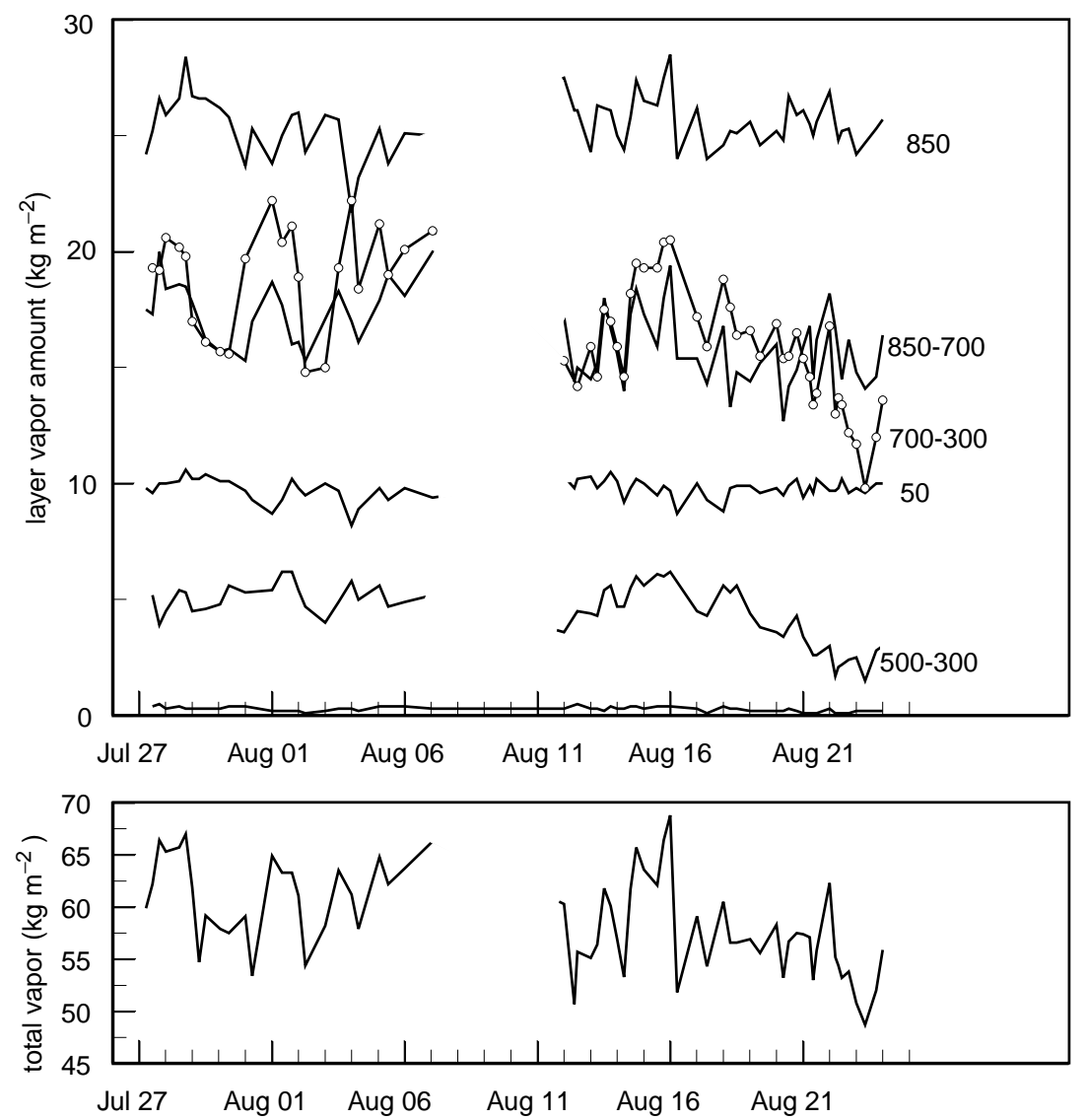

Figure 10. Variation of the water vapor amounts in different layers of the atmosphere. The number 50 in the label refers to the water vapor amount in the lowest $50 \mathrm{mb}$ layer ( atmospheric mixed layer), 850 to that between the surface and $850 \mathrm{mb}, 850-700$ to that between 850 and $700 \mathrm{mb}$, etc. The bottommost line is the water vapor amount above $300 \mathrm{mb}$.

evaporated from the underlying ocean in the lowest $1-2 \mathrm{kms}$ (convective boundary layer). Therefore this layer is normally rich in moisture and temporal variations in its moisture content are small. In fact, a small decrease (less than $2.5 \mathrm{~kg} \mathrm{~m}^{-2}$ ) is seen during the convective period in the amount of water vapor in the lowest $50 \mathrm{mb}$ layer. This is attributed to the downdrafts caused by precipitation, which brings the air having a lower amount of water vapor from above the boundary layer into the boundary layer (Knupp and Cotton 1985). As a result, the amount of water vapor in the lowest $50 \mathrm{mb}$ layer decreased. Due to strong winds that prevail during monsoon, evaporation rate is high and the convective boundary layer recovers its moisture content within a day (Bhat 2001). Owing to the strong vertical thermal stratification of the atmosphere, only deep convective clouds (cumulonimbus clouds) can transport moisture from low levels to the middle and upper troposphere. Therefore, moisture from the low levels is transported to the middle and upper troposphere only during the convective period, and the amount of water vapor increases during such periods. When convection ceases, subsidence prevails. Subsidence brings air from upper levels to lower levels and relative humidity decreases. In this process, the middle and upper troposphere become drier. Therefore, the amount of water vapor in $850-300 \mathrm{mb}$ layer critically depends on if convection is active or weak, and if not active, then on the time duration since convection. (If convection is active in a location, it changes the amount of water vapor in its surrounding area due to horizontal advection. Hence distance from the convective area is another important factor controlling the amount of moisture in the middle troposphere.) The saturation vapor pressure itself is very small at temperatures that prevail above $300 \mathrm{mb}$ level $\left(\sim-30^{\circ} \mathrm{C}\right.$ and lower $)$, and the amount of water vapor is small even if the atmosphere was fully saturated. Therefore, the fluctuations in the amount of water vapor above $300 \mathrm{mb}$ level are relatively small. It may be noted that, the small changes in the amount of water vapor that occur at these heights may be very important in certain problems such as radiative cooling of the atmosphere.

Upper winds are available for the second leg of BOBMEX only. Vertical profiles of the wind changed with synoptic conditions (Bhat et al 2001), 

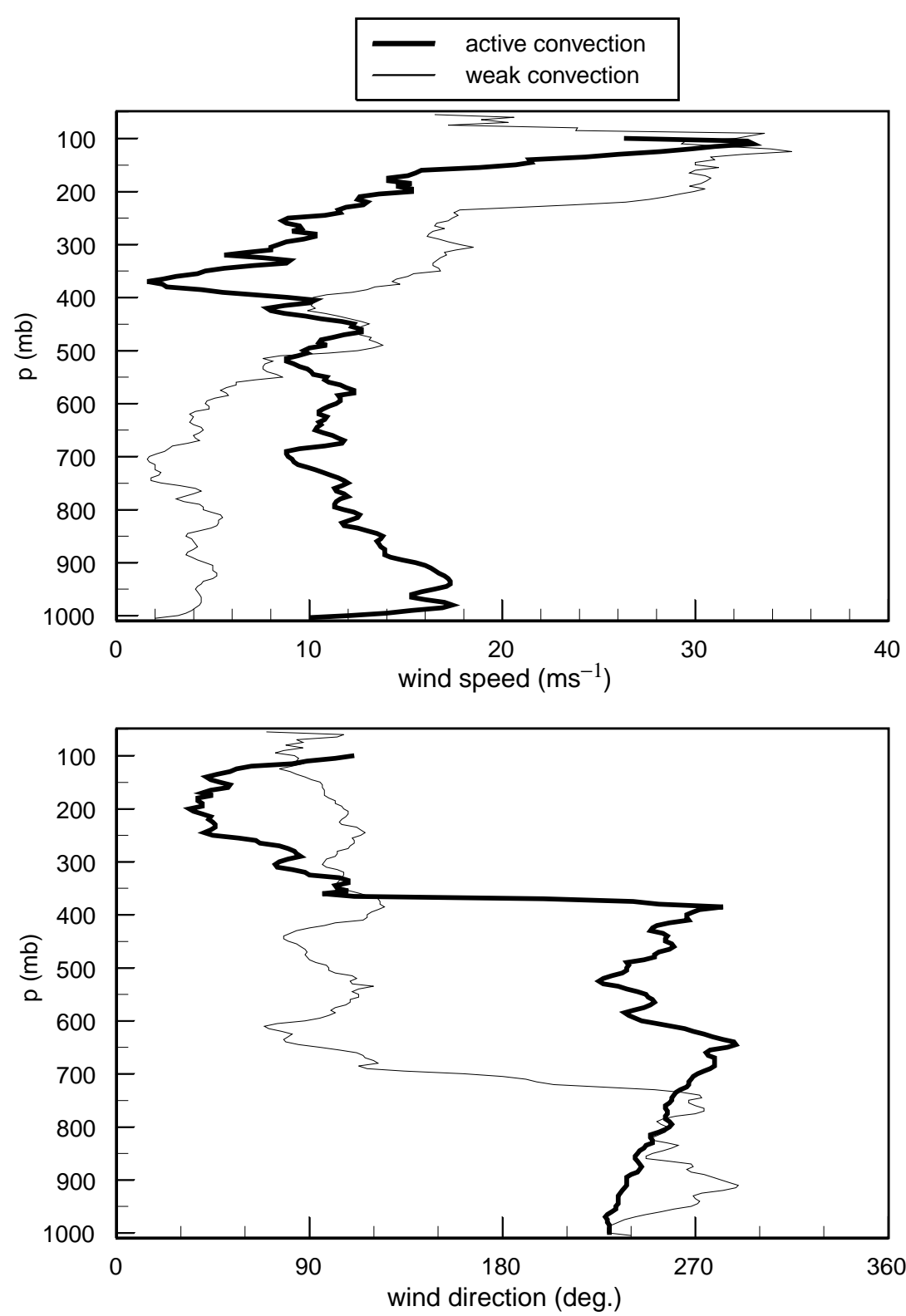

Figure 11. Typical profiles of wind speed and wind direction during active and weak phases of convection.

and here we consider a representative case for the active and weak convective periods. Figure 11 shows the vertical variation of wind speed and wind direction on 14th and 23rd August corresponding to the active and weak phases of convection respectively. In the lower troposphere, wind speed increased when the area was convectively active and decreased during the weak convective period. Easterly jet was narrower (but normally stronger) during the convectively active period, and the level of maximum wind also moved up. At low levels, westerly and southwesterly winds prevailed, and easterly winds were always present at upper levels $(\sim 200 \mathrm{mb})$. During the active period, southwesterly winds penetrated beyond $350 \mathrm{mb}$ height, whereas, as the weak convective conditions contin- ued, easterly winds gradually migrated down even below $650 \mathrm{mb}$ level. In general, the change from southwesterly to easterly wind direction took place abruptly, that is, the transition was sharp.

Another important issue was the fluctuations in the tropopause height in response to convection. Figure 12 shows the variations in the tropopause height and temperature, and the level and value of maximum wind at TS2. (Some radiosonde ascents did not reach up to the tropopause, and figure 12 includes only those ascents where the variables under consideration could be unambiguously determined.) Mean height of the tropopause was $100 \mathrm{mb}$ and the minimum temperature fluctuated between $-78^{\circ} \mathrm{C}$ and $-86^{\circ} \mathrm{C}$ with a mean of $-82^{\circ} \mathrm{C}$. Surprisingly, the tropopause height increased and the 

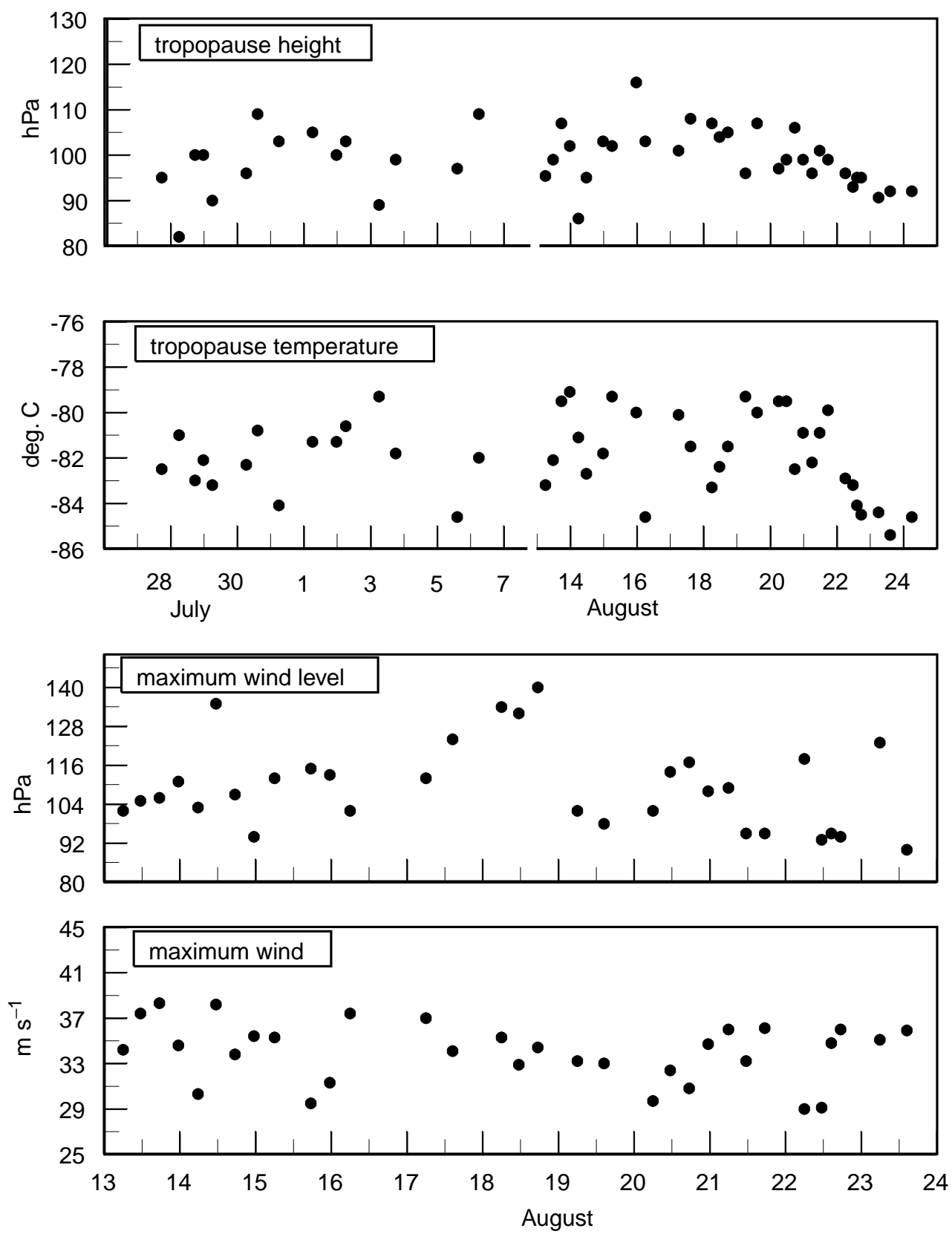

Figure 12. Variation of the tropopause level, tropopause temperature, level of maximum wind speed and maximum wind speed at TS2. Note the difference in the time axes between the top two and bottom two panels.

minimum temperature decreased during the weak convective phase (19th-24th August). (Normally, we expect the tropopause height to increase during the active phase of convection due to penetrating cumulonimbus clouds.) Height of the wind maximum fluctuated between $140 \mathrm{mb}$ and $90 \mathrm{mb}$, with a mean around $110 \mathrm{mb}$. Maximum wind speed varied between $29 \mathrm{~ms}^{-1}$ and $39 \mathrm{~ms}^{-1}$. No clear dependence of the maximum wind on the phase of convection is seen. (The upper wind time series is relatively short to make a very definite statement.) The major changes in the wind field are noticeable in the lower troposphere (Bhat et al 2001).

\section{Summary and conclusion}

For the first time, accurate measurements of atmospheric variables have been made during a peak monsoon period in the north Bay of Bengal under the BOBMEX programme. Data covering convectively active and weak phases were collected during BOBMEX. The present work described the atmospheric characteristics observed at $17.5^{\circ} \mathrm{N}, 89^{\circ} \mathrm{E}$ in the north Bay during JulyAugust 1999. Important conclusions are as follows.

- Convection influencing SST was clearly seen, and SST decreased by $0.4^{\circ} \mathrm{C}$ or more when daily 
rainfall exceeded $75 \mathrm{~mm}$. However, the extent to which SST influenced convection could not be established from BOBMEX observations.

- CAPE of the surface air decreased by $2-3 \mathrm{~kJ} \mathrm{~kg}^{-1}$ in response to deep convection and recovered in a time period of 1-2 days.

- One dimensional heat budget analysis revealed that horizontal advection is an important process in the north Bay governing SST evolution and vertical mixing is not important due to strong density stratification.

- There are important differences in the near surface characteristics between the monsoonal atmosphere over the north Bay and the west Pacific warm pool. Over the Indian Ocean itself, there is a strong seasonal dependence.

- During the convective period, the atmosphere cooled below $6 \mathrm{~km}$ and became warmer between $6 \mathrm{~km}$ and $13 \mathrm{~km}$ height. The amount of cooling/warming was less than $1.5^{\circ} \mathrm{C}$ relative to the observation period average temperature profile. The largest warming was located between $8 \mathrm{~km}$ and $10 \mathrm{~km}$ height, and the largest cooling was found just below $5 \mathrm{~km}$ height.

- The largest fluctuations in the humidity field occurred in the mid troposphere.

\section{Acknowledgements}

BOBMEX, the first observational experiment under the Indian Climate Research Program, was supported by the following Government of India agencies - Department of Science and Technology, Department of Ocean Development, Defence Research and Development Organization, and Department of Space. ORV Sagar Kanya was provided by the National Centre for Antarctica \& Ocean Research, Goa. It is a pleasure to thank the above mentioned agencies. I especially thank the India Meteorological Department for providing the INSAT data and also supporting BOBMEX. I appreciate the cooperation from other investigators in BOBMEX, namely, Dr. D Sengupta, Sri L V G Rao, Dr. Ramesh Babu and Dr. V S N Murty, and I thank them all. BOBMEX received advice and encouragement at different stages from Prof. Sulochana Gadgil, Prof. J Srinivasan, Sri. D R Sikka, Dr. S M Kulshrestha and Dr. R R Kelkar, and it is a great pleasure to thank them. Special thanks are due to other participants and ship crew who have helped in the collection of data; and to Mr. J V S Raju and Mr. Pulla Reddy for their help in launching the radiosondes and maintaining the sensors on the ship.

\section{References}

Betts A K 1976 J. Atmos. Sci. 33 1008-1020

Bhat G S 2001 Geophys. Res. Lett. 28 987-990

Bhat G S 2002 J. Geophys. Res. 107 10.1029/2001 JD000382

Bhat G S, Ameenulla S, Venkataramana M and Sengupta K 2000 Proc. Indian Acad Sci. Earth Planet. Sci. 109 $229-237$

Bhat G S, Gadgil S, Harish Kumar P V, Kalsi S R, Madhusoodanan P, Murty V S N, Prasada'Rao C V K, Ramesh Babu V, Rao L V G, Rao R R, Ravichandran M, Reddy K G, Sanjeeva Rao P, Sengupta D, Sikka D R, Swain J and Vinayachandran P N 2001 Bull. Amer. Meteor. Soc. 82 2217-2243

Bhat G S, Thomas M A, Raju J V S and Chandrasekhara C P 2003 Boundary Layer Meteorol. 106 263-281

Bradley E F, Godfrey J S, Coppin P A and Butt J A 1993 J. Geophys. Res. 98C 22521-22532

Chen S S and Houze R A Jr. 1997 Q. J. R. Meteor. Soc. 123 357-388

Fairall C W, Bradley E F, Rogers D P, Edson J B and Young G S 1996 J. Geophys. Res. 101C 3747-3764

Fairall C W, Bradley E F, Godfrey J S, Wick G A, Edson J B and Young G S 1996a J. Geophys. Res. 101C 1295-1308

Fein J S and Kuettner J P 1980 Bull. Amer. Meteor. Soc. 61 461-474

Gadgil S, Joseph P V and Joshi N V 1984 Nature 312 $141-143$

Gambheer A V and Bhat G S 2001 Meteorol. Atmos. Phys. 78 215-225

Godfrey J S, Houze R A Jr, Johnson R H, Lukas R, Redelsperger J L, Sumi A and Weller R 1998 J. Geophys. Res. 103C 3747-3764

Graham N E and Barnett T P 1987 Science 238 657-659

Hosom D S, Weller R A, Payne R E and Prada K E 1995 J. Atmos. Oceanic Technol. 12 527-540

Kingsmill D E and Houze R A Jr. 1999 Q. J. R. Meteorol. Soc. 125 1209-1229

Knupp K R and Cotton W R 1985 Rev. Geophys. 23 183-215

Krishnamurti T N 1985 Mon. Weather Rev. 113 1590-1626

Krishnamurti T N, Oosterhof D K and Mehta A V $1988 \mathrm{~J}$. Atmos. Sci. 45 1304-1322

Mitra A P 1999 Current Science 76 886-889

Mohanty U C and Das S 1986 Proc. Indian Natn. Sci. Acad. 52 625-640

Moncrief M W and Miller M J 1976 Q. J. R. Meteorol. Soc. $102373-394$

Paulson C A and Simpson J J 1981 J. Geophys. Res. 86 11044-11054

Premkumar K, Ravichandran M, Kalsi S R, Sengupta D and Gadgil S, 2000 Current Science 78 323-331

Vinayachandran P N, Murty V S N and Ramesh Babu V 2002 J. Geophys. Res. (Oceans) 107 10.1029/2002 JC001669

Waliser D A, Graham N E and Gautier C 1993 J. Climate 6 1405-1423

Webster P J and Lukas R 1992 Bull. Amer. Meteor. Soc. 73 1377-1416

Webster P J, Bradley E F, Fairall C E, Godfrey J S, Hacker P, Lucas R, Serra Y, Houze R A Jr., Humman J M, Lawrence T D M, Russel C A, Ryan M N, Sahami K and Zuidema P 2002 Bull. Amer. Meteor. Soc. 83 1603-1630

Zeng X, Zhao M and Dickinson R E 1998 J. Climate 11 $2628-2644$ 